\title{
Analiza isparavanja i kristalizacije kalijeva nitrata iz vodene otopine u dvostupnjevitom isparivačkom sustavu i vakuumskom kristalizatoru
}

\author{
E. Karić* i N. Mustafić \\ Katedra za hemijsko inženjerstvo, Tehnološki fakultet, Univerzitet u Tuzli \\ 75000 Tuzla, Bosna i Hercegovina
}

\begin{abstract}
Sažetak
U ovom radu prikazana je računalna analiza razdvajanja soli iz dvokomponentnog elektrolitskog sustava. Elektrolitski sustav $\mathrm{KNO}_{3}-\mathrm{H}_{2} \mathrm{O}$ primijenjen je kao "case study" za prikazivanje analize procesa isparavanja i kristalizacije. Sljedeći procesi uzeti su u obzir: dvostupnjeviti isparivački sustav i vakuumski kristalizator s adijabatskim hlađenjem. Razvijen je matematički model dvostupnjevitog isparivačkog sustava i vakuumskog kristalizatora. Matematički model sastoji se od algebarskih jednadžbi. Predloženi model razvijen je u programu Microsoft Excel s VBA (Visual Basic for Applications). Razvijeni model omogućava analizu postojećeg ili dizajniranje novog procesa isparavanja i kristalizacije. Razvijeni model može biti primijenjen na bilo koji dvokomponentni elektrolitski sustav, ali zahtijeva unošenje fizikalno-kemijskih svojstava odgovarajućeg elektrolitskog sustava.

Ključne riječi

Elektrolitski sustav, isparivački sustav, vakuumska kristalizacija, matematički model
\end{abstract}

\section{Uvod}

Isparavanje predstavlja prijenos kapljevite hlapljive komponente u plinovitu fazu uslijed prijenosa topline. ${ }^{1}$ Kristalizacija se primjenjuje u mnogim organskim i gotovo svim anorganskim, kemijskim proizvodnim postrojenjima gdje željeni proizvod predstavlja fino razdvojenu čvrstu supstanciju. ${ }^{1}$ Oba navedena procesa zahtijevaju potrošnju pogonskih sredstava. Kombinacija procesa isparavanja $\mathrm{i}$ kristalizacije vrlo se često primjenjuje za izdvajanje soli iz višekomponentnih elektrolitskih sustava. Osnovni zahtjevi koji se postavljaju procesu kristalizacije iz otopine svode se na osiguravanje minimalnog utroška energije i maksimalnog specifičnog kapaciteta kristalizatora $u$ uvjetima dobivanja proizvoda potrebnog stupnja čistoće i raspodjele veličina čestica. ${ }^{2} U$ radu Jotanovića $i$ Suljkanovića ${ }^{2}$ provedena je analiza procesa kristalizacije natrijeva klorida iz njegovih vodenih otopina u vakuumskom kristalizatoru $\mathrm{s}$ recirkulacijom suspenzije $\mathrm{s}$ ciljem razrade inženjerskih metoda proračuna odgovarajućeg mehanizma procesa kristalizacije.

U radu Thomsena $i$ sur. ${ }^{3}$ prikazane su metode za rješavanje različitih tipova faznih dijagrama za vodene elektrolitske sustave s pouzdanim tehnikama za simulaciju, dizajn $\mathrm{i}$ optimizaciju frakcijskih procesa kristalizacije. Za sve proračune primijenili su prošireni model UNIQUAC. ${ }^{4}$
Fitch $^{5}$ je opisao grafički prikaz metoda za dizajn frakcijskog procesa kristalizacije na temelju faznih dijagrama topljivosti. Za povećanje koncentracije otopine primjenjuje se višestupnjeviti isparivački sustav. ${ }^{6} \mathrm{U}$ proizvodnji svježe vode procesom desalinizacije, energetski troškovi za višestupnjevito isparavanje su $20-30 \%$ od ukupne cijene vode. ${ }^{7} U$ industrijskom mjerilu vakuumska kristalizacija jedna je od najčešće primjenjivanih kristalizacijskih tehnika, kako pri kristalizaciji individualnih komponenata tako i u procesima frakcijske kristalizacije iz višekomponentnih elektrolitskih sustava. ${ }^{8} \mathrm{U}$ radu Hillenbranda $i$ Westerberga ${ }^{9}$ razvijen je analitički alat za računanje minimalne potrošnje pogonskih sredstava u višestupnjevitom isparivačkom sustavu koji je toplinski integriran s procesnim tokovima. Nishitani $i$ Kunugita $^{10}$ istraživali su jednostupnjeviti isparivač $u$ kombinaciji s kondenzatorom i izmjenjivačem topline, uz predrgijavanje pojnog toka parom iz isparivača. Radni uvjeti za sustav izabrani su na temelju ovisnosti godišnjih investicijskih troškova o godišnjoj potrošnji energije. U radu Kumara $i$ sur. ${ }^{11}$ dobiven je matematički model temeljen na linearnim i nelinearnm jednadžbama bilance tvari i energije, koji se može primijeniti za bilo koji broj stupnjeva isparavanja i za bilo koje polazne uvjete. S ciljem smanjenja potrošnje energije u procesu koncentriranja voćnog soka, u radu Ruana $i$ sur. ${ }^{12}$ razvijen je opći matematički model višestupnjevitog isparivačkog sustava.

\footnotetext{
*Autor za dopisivanje: Ervin Karić

e-pošta: ervin.karic@untz.ba
} 
Jednadžbe bilance tvari i energije opisane su u matričnom obliku s ciljem boljeg razumijevanja modela. ${ }^{12}$

U ovom radu prikazan je razvoj matematičkog modela za razdvajanje soli iz dvokomponentnog elektrolitskog sustava $\mathrm{KNO}_{3}-\mathrm{H}_{2} \mathrm{O}$. Za razvijeni matematički model napravljen je procesni simulator u programu Microsoft Excel s VBA. Proces isparavanja predstavljen je u dva isparivačka stupnja i s ciljem uštede energije, generirana sekundarna para iz prvog isparivačkog stupnja upotrijebila se kao pogonsko sredstvo u drugom isparivačkom stupnju. Prikazana je bilanca tvari i energije isparivačkog i kristalizacijskog sustava. Također su prikazane specifične entalpije svakog procesnog toka. Model omogućava računanje potrošnje pogonskih sredstava, masenog protoka i specifične entalpije svakog procesnog toka, temperature i tlaka u prvom isparivačkom stupnju te površinu izmjene topline i prenesenu toplinu u svakom isparivačkom stupnju. Dostupno je vrlo malo literature koja opisuje kombinaciju procesa isparavanja i kristalizacije. Cilj rada bio je na konkretnom primjeru povezati navedene procese $\mathrm{s}$ matematičkim opisom oba procesa. Rezultati ovog rada mogu poslužiti kao smjernice za poboljšanje rada u navedenim procesima bez potrebe za skupim eksperimentima na samom postrojenju. Razvijeni model može biti primijenjen na bilo koji dvokomponentni elektrolitski sustav, ali zahtijeva unošenje fizikalnokemijskih svojstava odgovarajućeg elektrolitskog sustava.

\subsection{Teorijski dio}

Procesni tok koji treba zbrinuti predstavlja višekomponentni elektrolitski sustav $\mathrm{KNO}_{3}-\mathrm{H}_{2} \mathrm{O}$. Parametri toka su sljedeći: protok $8,5 \mathrm{~m}^{3} \mathrm{~h}^{-1}$, sadržaj soli 0,078 množinskih udjela i temperatura $25{ }^{\circ} \mathrm{C}$. Procesni sustav treba kreirati kao uniju dvaju podsustava: podsustava koncentriranja i podsustava kristalizacije. Podsustav koncentriranja treba koncipirati s ciljem dovođenja sustava do stanja zasićenja, pri čemu tlak isparavanja može poprimiti vrijednosti $0,1 \leq p \leq 1,0$ bar. Kao procesne alternative podsustavu koncentriranja treba razmotriti izvođenje procesa isparavanja $u$ dva stupnja, $u$ rednoj vezi u odnosu na otopinu i s međusobno jednakim površinama za prijenos topline. Kao moguća kristalizacijska tehnika razmotrena je vakuumska kristalizacija. Tlak u kristalizatoru može poprimiti vrijednosti $0,005 \leq p \leq 0,1$ bar. Sadržaj vlage u kristalnom produktu ne smije biti veći od 0,03 množinskih udjela. Na raspolaganju su energenti u dovoljnim količinama: zasićena vodena para tlaka 15,0 bar. Potrebno je odrediti potrošnju ogrjevne pare.

\section{Matematički opis procesa}

$U$ skladu $\mathrm{s}$ formulacijom problema prikazanim $\mathrm{u}$ teorijskom dijelu može se izvesti procesna shema koja se sastoji od dva isparivačka stupnja i jednog vakuumskog kristalizatora, prikazana na slici 1.

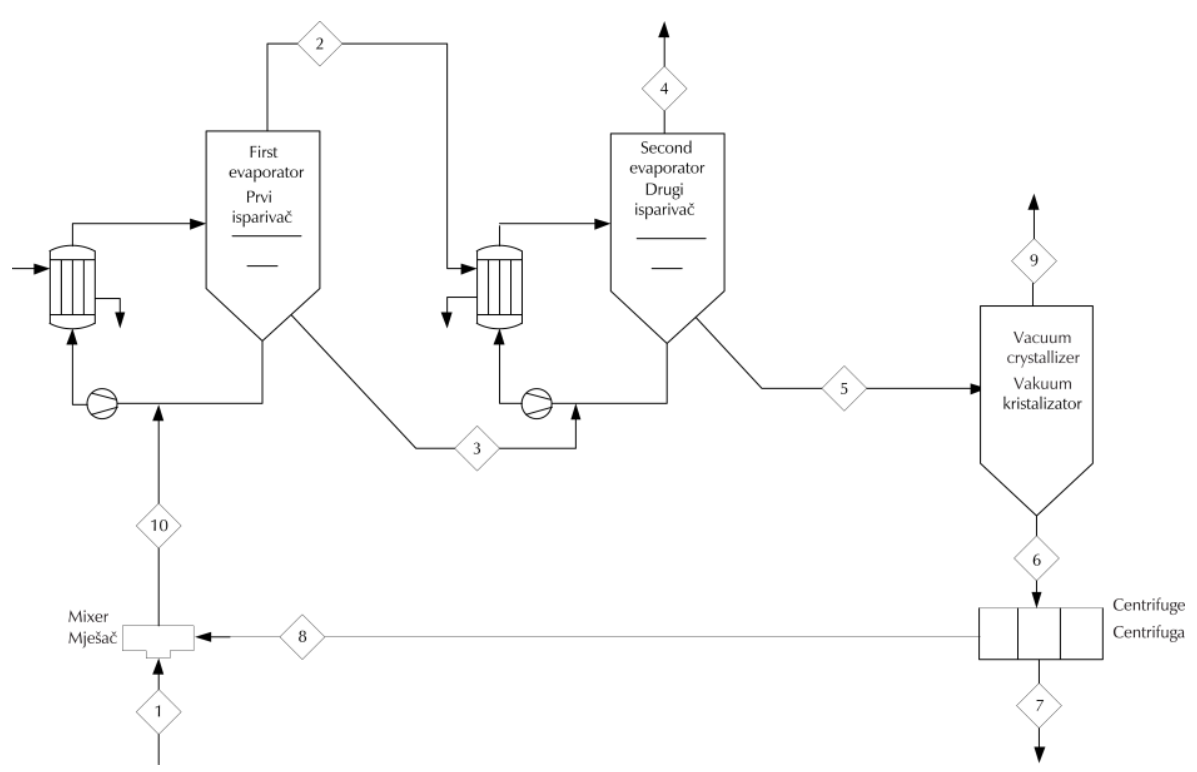

Slika 1 - Shema procesa s dva isparivačka stupnja i jednim vakuumskim kristalizatorom: 1 - pojni tok, 2 - tok isparene vode u prvom isparivačkom stupnju, 3 - koncentrirani tok na izlazu iz prvog isparivačkog stupnja, 4 - tok isparene vode u drugom isparivačkom stupnju, 5 - koncentrirani tok na izlazu iz drugog isparivačkog stupnja, 6 - tok suspenzije, 7 - tok kristalnog produkta, 8 - tok matične otopine, 9 - tok sekundarne pare generirane u vakuumskom kristalizatoru, 10 - tok nakon miješanja tokova 1 i 8.

Fig. 1 - Scheme of the process with two evaporative stages and one vacuum crystallizer: 1 - feed flow, 2 - stream of evaporated water in the first evaporation step, 3 - outlet concentrated flow from the first evaporator stage, 4 - flow of evaporated water in the second evaporator stage, 5 - outlet concentrated flow from the second evaporator stage, 6 - suspension flow, 7 crystal product flow, 8 - parent solution flow, 9 - secondary steam flow generated in the vacuum crystallizer, 10 - flow after mixing flows 1 and 8 . 
Dodjeljuju se oznake za indekse koji se upotrebljavaju u simbolima za sadržaj soli u procesnim tokovima:

$1-\mathrm{KNO}_{3}$

$2-\mathrm{H}_{2} \mathrm{O}$

Da bi se odredila temperatura i sadržaj $\mathrm{KNO}_{3}$ u stanju zasićenja, potrebno je znati tlak para iznad vodene otopine $\mathrm{KNO}_{3}$. Tlak para, iznad zasićenih otopina $\mathrm{KNO}_{3}$, u ovisnosti o temperaturi prikazan je u tablici 1.

Tablica 1 - Tlak para, iznad zasićenih otopina $\mathrm{KNO}_{3}$, u ovisnosti o temperaturi ${ }^{13}$

Table 1 - Vapour pressure, above saturated $\mathrm{KNO}_{3}$ solutions, depending on temperature ${ }^{13}$

\begin{tabular}{c|c}
\hline$t /{ }^{\circ} \mathrm{C}$ & $\mathrm{p} / \mathrm{mmHg}$ \\
\hline 10,0 & 7,1 \\
20,0 & 13,0 \\
25,0 & 17,4 \\
30,0 & 22,9 \\
40,0 & 38,6 \\
50,0 & 62,3 \\
60,0 & 97,2 \\
70,0 & 146,4 \\
80,0 & 213,9 \\
90,0 & 303,9 \\
100,0 & 420,5 \\
110,0 & 567,8 \\
115,0 & 654,0 \\
120,0 & 749,2 \\
\hline
\end{tabular}

Za izračun temperature u kristalizatoru primijenjena je Antoineova korelacija prikazana jedn. (1):

$$
\ln p(\mathrm{mmHg})=A-\frac{B}{t\left({ }^{\circ} \mathrm{C}\right)+C}
$$

Određivanje parametara Antoineove korelacije izvodi se u skladu s algoritamskim koracima prikazanim na slici 2.

Sustav jednadžbi (2-13) primjenjuje se za određivanje Antoineovih parametara.

$$
\begin{gathered}
z_{\mathrm{i}}=t_{\mathrm{i}} \\
x_{\mathrm{i}}=1 / \ln (p) \\
y_{\mathrm{i}}=t_{\mathrm{i}} / \ln (p)
\end{gathered}
$$

$$
\begin{gathered}
A A=\sum_{i=1}^{n} x_{i}^{2}-\left(\sum_{i=1}^{n} x_{i}\right)^{2} / n \\
B B=\sum_{i=1}^{n} x_{i} \cdot y_{i}-\sum_{i=1}^{n} x_{i} \cdot \sum_{i=1}^{n} y_{i} / n
\end{gathered}
$$

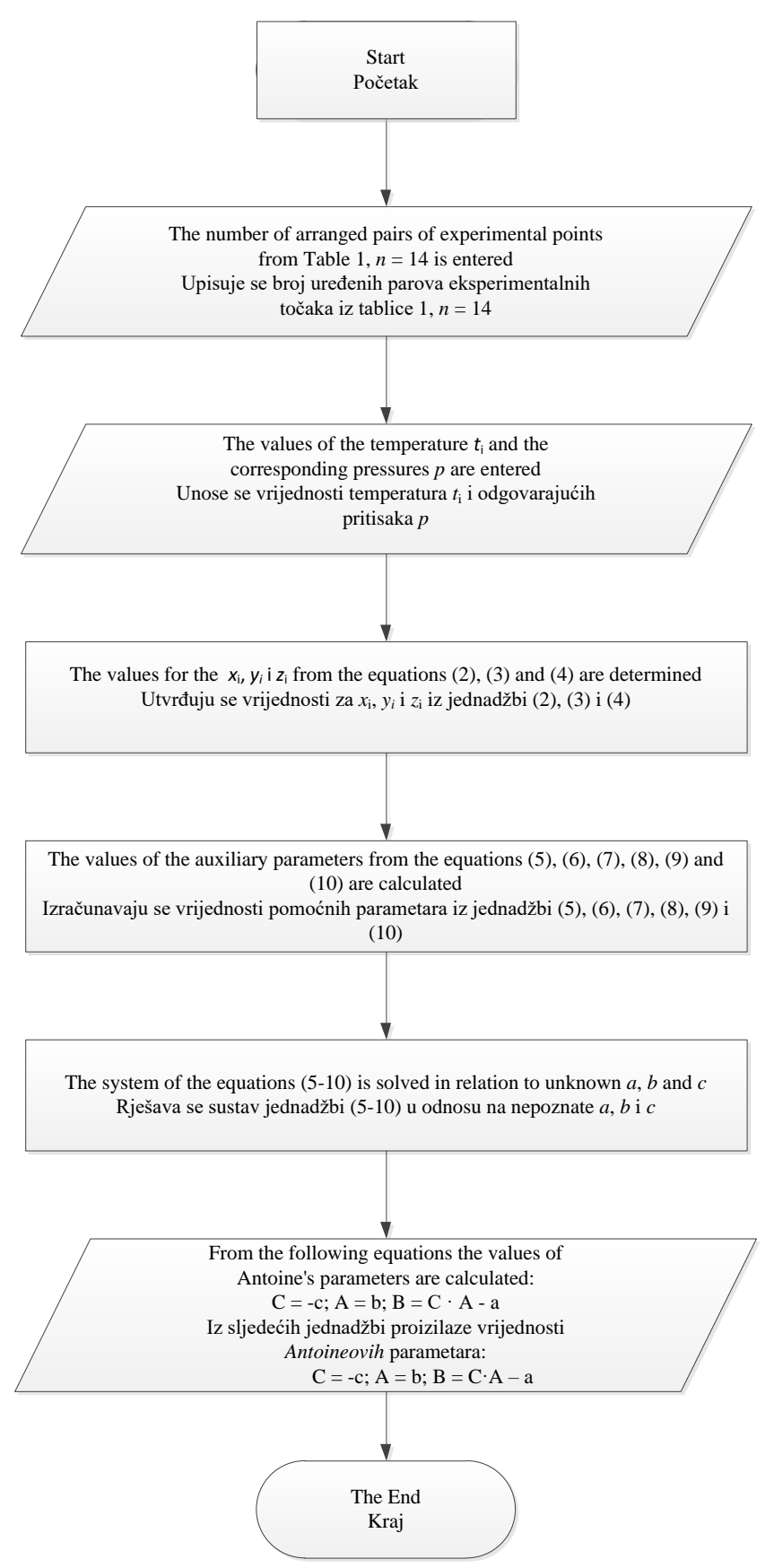

Slika 2 - Algoritamski koraci za utvrđivanje Antoineovih parametara

Fig. 2 - Algorithmic steps for the determination of Antoine's parameters 


$$
\begin{gathered}
C C=\sum_{i=1}^{n} x_{i} \cdot z_{i}-\sum_{i=1}^{n} x_{i} \cdot \sum_{i=1}^{n} z_{i} / n \\
D D=\sum_{i=1}^{n} x_{i} \cdot y_{i}-\sum_{i=1}^{n} x_{i} \cdot \sum_{i=1}^{n} y_{i} / n \\
E E=\sum_{i=1}^{n} y_{i}^{2}-\left(\sum_{i=1}^{n} y_{i}\right)^{2} / n \\
F F=\sum_{i=1}^{n} z_{i} \cdot y_{i}-\sum_{i=1}^{n} z_{i} \cdot \sum_{i=1}^{n} y_{i} / n \\
b=\left(F F-\frac{B B}{A A} \cdot C C\right) /\left(E E-\frac{B B^{2}}{A A}\right) \\
a=(C C-b \cdot B B) / A A \\
C=\left(\sum_{i=1}^{n} z_{i}-a \cdot \sum_{i=1}^{n} x_{i}-b \cdot \sum_{i=1}^{n} y_{i}\right) / n
\end{gathered}
$$

Za poznati tlak u kristalizatoru, temperatura kristalizatora $\mathrm{i}$ sadržaj soli u otopini određuju se iz jedn. (1) i (15):

$$
c_{1}^{(8)}=0,0979+0,0081 \cdot t_{\mathrm{kr}}-0,00002 \cdot t_{\mathrm{kr}}^{2}
$$

Jedn. (15) predstavlja ovisnost sadržaja soli u stanju zasićenja o temperaturi.

Koncentracija soli u kristalnom produktu se određuje iz jednadžbe (16).

$$
c_{1}^{(7)}=(1-0,03) \cdot c_{1}^{(k r)}+\left(0,03 \cdot c_{1}^{(8)}\right)
$$

Za poznati tlak u drugom isparivaču temperatura u drugom isparivaču i sadržaj soli u koncentriranom toku određuju se iz jedn. (1) i (17).

$$
c_{1}^{(8)}=0,0979+0,0081 \cdot t_{\text {isp }} I-0,00002 \cdot t_{\text {isp }}^{2} I
$$

$\mathrm{U}$ skladu $\mathrm{s}$ formulacijom problema prikazanom $\mathrm{u}$ teorijskom dijelu može se izvesti struktura cijelog sustava prikazana na slici 3.

Ukupna bilanca tvari prikazana je jedn. (18).

$$
\bar{m}_{1}=\bar{m}_{\mathrm{w}}+\bar{m}_{7}
$$

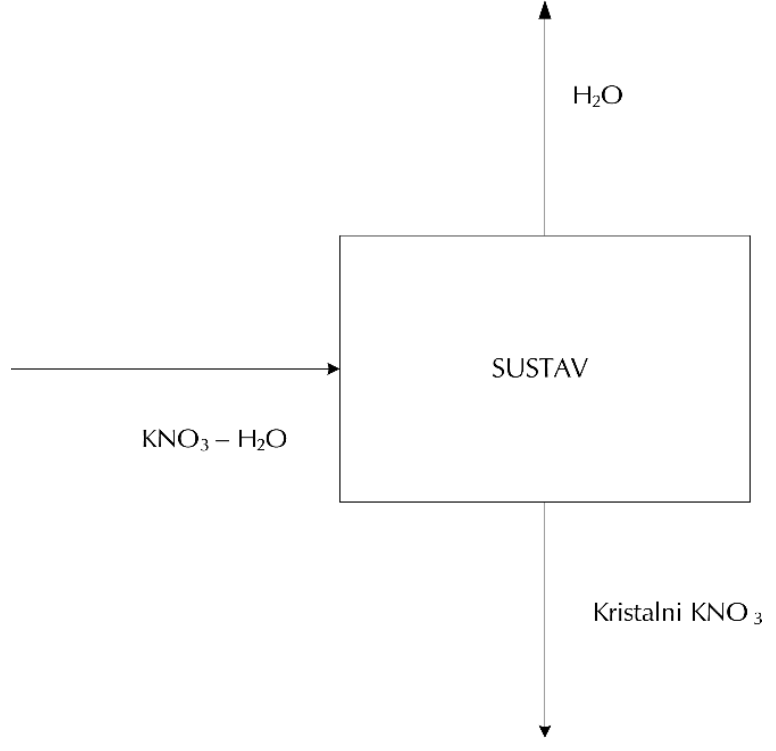

Slika 3 - Struktura cijelog sustava

Fig. 3 - Structure of the entire system

Ukupna bilanca tvari u odnosu na $\mathrm{KNO}_{3}$ prikazana je jedn. (19).

$$
\bar{m}_{1} \cdot C_{1}^{(1)}=\bar{m}_{7} \cdot C_{1}^{(7)}
$$

Bilanca tvari podsustava kristalizacije prikazana je jedn. (20).

$$
\bar{m}_{5}=\bar{m}_{7}+\bar{m}_{8}+\bar{m}_{9}
$$

Bilanca tvari podsustava kristalizacije u odnosu na $\mathrm{KNO}_{3}$ prikazana je jedn. (21).

$$
\bar{m}_{5} \cdot c_{1}^{(5)}=\bar{m}_{7} \cdot c_{1}^{(7)}+\bar{m}_{8} \cdot c_{1}^{(8)}
$$

Toplinska bilanca podsustava kristalizacije prikazana je jedn. (22).

$$
\bar{m}_{5} \cdot \hat{h}_{5}+\bar{m}_{7} \cdot q_{\mathrm{kr}}=\bar{m}_{8} \cdot \hat{h}_{8}+\bar{m}_{7} \cdot \hat{h}_{7}+\bar{m}_{9} \cdot \hat{H}_{9}
$$

Specifične entalpije toka kristalnog produkta i toka matične otopine za referentnu temperaturu: $t_{\text {ref }}=0{ }^{\circ} \mathrm{C}$ prikazane su jedn. (23).

$$
\hat{h}_{\mathrm{i}}=\int_{t_{\text {tef }}}^{t_{\mathrm{kr}}} C_{\mathrm{p}^{\prime \prime}}(t) d t i=7,8
$$

Specifična entalpija koncentriranog toka na izlazu iz drugog isparivača za referentnu temperaturu $t_{\text {ref }}=0{ }^{\circ} \mathrm{C}$ prikazana je jedn. (24).

$$
\hat{h}_{5}=\int_{t_{\text {tef }}}^{t_{\text {ispl }}} c_{\mathrm{p}, 5}(t) d t
$$


Specifična entalpija toka generirane sekundarne pare za referentnu temperaturu $t_{\text {ref }}=0{ }^{\circ} \mathrm{C}$ prikazana je jedn. (25).

$$
\hat{H}_{9}=f\left(t_{\mathrm{kr}}\right)
$$

Bilanca tvari prvog isparivačkog stupnja prikazana je jedn. (26).

$$
\bar{m}_{1}+\bar{m}_{8}=\bar{m}_{2}+\bar{m}_{3}
$$

Bilanca tvari prvog isparivačkog stupnja u odnosu na $\mathrm{KNO}_{3}$ prikazana je jedn. (27).

$$
\bar{m}_{1} \cdot c_{1}^{(1)}+\bar{m}_{8} \cdot c_{1}^{8}=\bar{m}_{3} \cdot c_{1}^{(3)}
$$

Bilanca topline prvog isparivačkog stupnja prikazana je jedn. (28).

$$
\bar{m}_{1} \cdot \hat{h}_{1}+\bar{m}_{8} \cdot \hat{h}_{8}+Q_{\mathrm{tr}}^{(1)}=\bar{m}_{2} \cdot \hat{H}_{2}+\bar{m}_{3} \cdot \hat{h}_{3}
$$

Temperatura isparavanja u prvom isparivačkom stupnju prikazana je jedn. (29).

$$
t_{\text {isp }} \mathrm{I}=t_{\mathrm{w}}+\mathrm{d} t
$$

gdje I označava prvi isparivački stupanj.

Vrijednost za veličinu površine prijenosa topline prvog isparivačkog stupnja dana je jedn. (30).

$$
A_{1}=\frac{Q_{\mathrm{tr}}^{(1)}}{K_{\mathrm{l}} \cdot \Delta t_{\mathrm{sr}}^{(1)}}
$$

Vrijednost koeficijenta prijenosa topline $u$ prvom isparivačkom stupnju $K_{\mathrm{I}}$ je pretpostavljena i iznosi $1200 \mathrm{~W} \mathrm{~m}^{-2} \mathrm{~K}^{-1}$.

Srednja temperaturna razlika prvog isparivačkog stupnja prikazana je jedn. (31).

$$
\Delta t_{\text {sr }}^{(l)}=t_{\text {rp }}-t_{\text {isp }} \text { I }
$$

Povišenje vrelišta prikazano je jedn. (32).

$$
\mathrm{d} t=29,669 \cdot \mathrm{c}_{1}^{(3) 2}-6,2011 \cdot \mathrm{c}_{1}^{(3)}+1,6308
$$

Potrošnja ogrjevne pare prikazana je jedn. (33).

$$
Q_{\mathrm{tr}}^{(\mathrm{l})}=\bar{m}_{\mathrm{op}} \cdot \Delta \hat{H}_{\mathrm{v}}^{(\mathrm{l})}
$$

Količina prenesene topline u drugom isparivačkom stupnju prikazana je jedn. (34).

$$
Q_{\mathrm{tr}}^{(\mathrm{III})}=\bar{m}_{2} \cdot \Delta \hat{H}_{\mathrm{v}}^{\left(\mathrm{t}_{\mathrm{isp}} \mathrm{l}\right)}
$$

Bilanca tvari drugog isparivačkog stupnja prikazana je jedn. (35).

$$
\bar{m}_{3}=\bar{m}_{4}+\bar{m}_{5}
$$

Bilanca tvari drugog isparivačkog stupnja u odnosu na $\mathrm{KNO}_{3}$ prikazana je jedn. (36).

$$
\bar{m}_{3} \cdot c_{1}^{(3)}=\bar{m}_{5} \cdot c_{1}^{(5)}
$$

Bilanca topline drugog isparivačkog stupnja prikazana je jedn. (37).

$$
\bar{m}_{3} \cdot \hat{h}_{3}+Q_{\mathrm{tr}}^{(\mathrm{II})}=\bar{m}_{5} \cdot \hat{h}_{5}+\bar{m}_{4} \cdot \hat{H}_{4}
$$

Srednja temperaturna razlika u drugom isparivačkom stupnja proizlazi iz jedn. (38).

$$
Q_{\mathrm{tr}}^{(\mathrm{II})}=K_{\mathrm{II}} \cdot A_{\mathrm{ll}} \cdot \Delta t_{\mathrm{sr}}^{(\mathrm{II})}
$$

Vrijednost koeficijenta prijenosa topline $u$ drugom isparivačkom stupnju $K_{\text {II }}$ pretpostavljena je i iznosi $900 \mathrm{~W} \mathrm{~m}^{-2} \mathrm{~K}^{-1}$.

Temperatura isparavanja iz prvog isparivačkog stupnja proizlazi iz jedn. (39).

$$
\Delta t_{\text {sr }}^{(I I)}=t_{\text {isp }} \mathrm{I}-t_{\text {isp }} \text { II }
$$

Sustav jednadžbi je riješen u programu Microsoft Excel s VBA.

\section{Rezultati i rasprava}

Rješavanjem sustava jednadžbi (2-13) dobivaju se vrijednosti parametara u Antoineovoj korelaciji $(A=15,53$, $B=2842,06, C=199,31$ ). Tlak u prvom isparivačkom stupnju iznosi 0,78 bar. Preostali rezultati prikazani su u tablici 2.

S ciljem povećanja sadržaja soli na ulazu u prvi isparivač, tok matične otopine miješa se s polaznim tokom prije ulaza u prvi isparivački stupanj. Rezultati su dobiveni metodom iteracije. Temperatura u prvom isparivačkom stupnju uzeta je kao prva iterativna varijabla i pretpostavljena joj je neka vrijednost veća od temperature u drugom isparivačkom stupnju na zadanom tlaku. Kao druga iterativna varijabla uzet je sadržaj soli u koncentriranom toku prvog isparivačkog stupnja i pretpostavljena joj je neka vrijednost veća od sadržaja soli u toku 1. Pomoću jedn. (36) provedena je provjera druge iterativna varijable, dok je pomoću jedn. (39) provedena provjera prve iterativne varijable. Potrošnja ogrjevne pare u prvom isparivačkom stupnju iznosi 4777,83 $\mathrm{kg} \mathrm{h}^{-1}$, dok u drugom isparivačkom stupnju nema potrošnje ogrjevne pare s obzirom na to da 
se kao pogonsko sredstvo upotrebljava generirana sekundarna para iz prvog isparivačkog stupnja. Miješanjem polaznog toka sa sadržajem soli od 0,078 množinskih udjela i toka matične otopine sa sadržajem soli od 0,230 množinskih udjela dobiva se tok 10 sa sadržajem soli od 0,130 množinskih udjela. Miješanje navedenih tokova ima cilj povećati sadržaj soli u toku koji ulazi u prvi isparivački stupanj. Navedeni tokovi mogu se miješati samo ukoliko je sadržaj soli u toku matične otopine veći od sadržaja soli u polaznom sustavu.

Tablica 2 - Rezultati rješenja sustava jednadžbi (13-39)

Table 2 - Results of the solution for the system of equations (13-39)

\begin{tabular}{|c|c|}
\hline \multicolumn{2}{|l|}{$\begin{array}{l}\text { Generirana sekundarna para prvog } \\
\text { isparivačkog stupnja - tok } 2 \\
\text { Generated secondary vapour of the } \\
\text { first evaporator stage - stream } 2\end{array}$} \\
\hline $\begin{array}{l}\text { protok, } \mathrm{kg} \mathrm{h}^{-1} \\
\text { flow, } \mathrm{kg} \mathrm{h}^{-1}\end{array}$ & 4288,16 \\
\hline $\begin{array}{l}\text { specifična entalpija, } \mathrm{kJ} \mathrm{kg}^{-1} \\
\text { specific enthalpy, } \mathrm{kJ} \mathrm{kg}^{-1}\end{array}$ & 2662,53 \\
\hline \multicolumn{2}{|c|}{$\begin{array}{l}\text { Koncentrirani tok prvog isparivačkog stupnja - tok } 3 \\
\text { Concentrated flow of the first evaporator stage - stream } 3\end{array}$} \\
\hline $\begin{array}{l}\text { protok toka, } \mathrm{kgh}^{-1} \\
\text { flow, } \mathrm{kg} \mathrm{h}^{-1}\end{array}$ & 10562,44 \\
\hline $\begin{array}{l}\text { sadržaj soli iskazan množinskim udjelom (1) } \\
\text { salt content expressed in multiplier share (1) }\end{array}$ & 0,27 \\
\hline $\begin{array}{l}\text { specifična entalpija, } \mathrm{kJ} \mathrm{kg}^{-1} \\
\text { specific enthalpy, } \mathrm{kJ} \mathrm{kg}^{-1}\end{array}$ & 353,04 \\
\hline \multicolumn{2}{|c|}{$\begin{array}{l}\text { Generirana sekundarna para drugog isparivačkog stupnja - tok } 4 \\
\text { Generated secondary vapour of the } \\
\text { second evaporator stage - stream } 4\end{array}$} \\
\hline $\begin{array}{l}\text { protok, } \mathrm{kgh}^{-1} \\
\text { flow, } \mathrm{kg} \mathrm{h}^{-1}\end{array}$ & 3679,17 \\
\hline $\begin{array}{l}\text { specifična entalpija, } \mathrm{kJ} \mathrm{kg}^{-1} \\
\text { specific enthalpy, } \mathrm{kJ} \mathrm{kg}^{-1}\end{array}$ & 2586,75 \\
\hline \multicolumn{2}{|c|}{$\begin{array}{l}\text { Koncentrirani tok drugog isparivačkog stupnja - tok } 5 \\
\text { Concentrated flow of the second evaporator stage - stream } 5\end{array}$} \\
\hline $\begin{array}{l}\text { protok, } \mathrm{kgh}^{-1} \\
\text { flow, } \mathrm{kg} \mathrm{h}^{-1}\end{array}$ & 6883,27 \\
\hline $\begin{array}{l}\text { sadržaj soli iskazan množinskim udjelom (1) } \\
\text { salt content expressed in multiplier share (1) }\end{array}$ & 0,29 \\
\hline $\begin{array}{l}\text { specifična entalpija, } \mathrm{kJ} \mathrm{kg}^{-1} \\
\text { specific enthalpy, } \mathrm{kJ} \mathrm{kg}^{-1}\end{array}$ & 135,98 \\
\hline \multicolumn{2}{|l|}{$\begin{array}{l}\text { Tok kristalnog produkta }- \text { tok } 7 \\
\text { Crystal product flow }- \text { stream } 7\end{array}$} \\
\hline $\begin{array}{l}\text { protok, } \mathrm{kgh}^{-1} \\
\text { flow, } \mathrm{kg} \mathrm{h}^{-1}\end{array}$ & 528,61 \\
\hline $\begin{array}{l}\text { sadržaj soli iskazan množinskim udjelom (1) } \\
\text { salt content expressed in multiplier share (1) }\end{array}$ & 0,98 \\
\hline $\begin{array}{l}\text { specifična entalpija, } \mathrm{kJ} \mathrm{kg}^{-1} \\
\text { specific enthalpy, } \mathrm{kJ} \mathrm{kg}^{-1}\end{array}$ & 131,41 \\
\hline
\end{tabular}

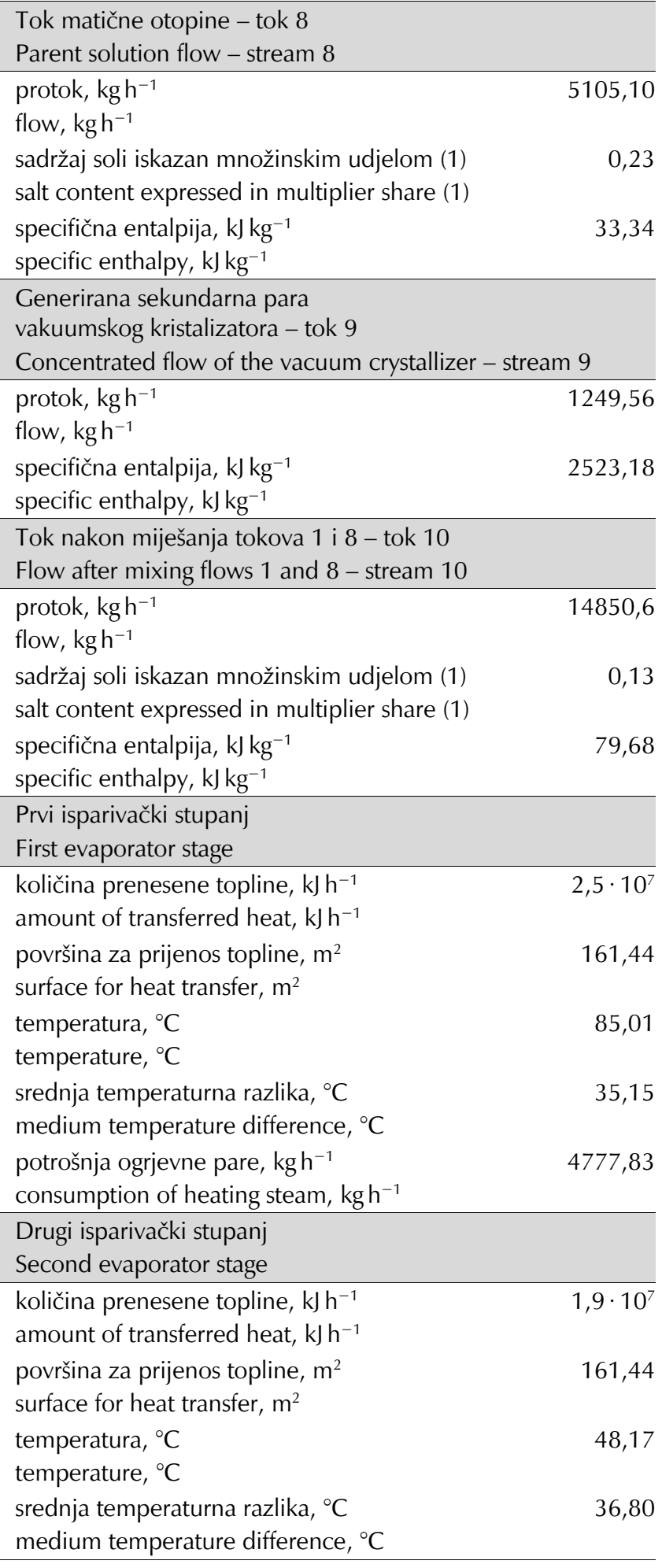

Količina prenesene topline u prvom isparivačkom stupnju veća je u odnosu na količinu prenesene topline u drugom isparivačkom stupnju, pa se znatno više soli koncentrira (od 0,13 do 0,27 množinskih udjela) u prvom nego u drugom isparivačkom stupnju. U drugom isparivačkom stupnju dolazi do koncentriranja soli od 0,27 do 0,29 množinskih udjela. Za grijanje prvog isparivačkog stupnja upotrebljava 
se ogrjevna para $\left(4777,83 \mathrm{kgh}^{-1}\right)$, dok se kao ogrjevni medij u drugom isparivačkom stupnju upotrebljava generirana sekundarna para iz prvog isparivačkog stupnja s protokom od 3228,16 $\mathrm{kg} \mathrm{h}^{-1}$, što također objašnjava veću količinu transferirane topline u prvom isparivačkom stupnju. Razvijeni model omogućava analizu postojećeg ili dizajniranje novog isparivačkog i kristalizacijskog procesa. Razvijeni model može biti primijenjen na bilo koji dvokomponentni elektrolitski sustav, ali zahtijeva unošenje fizikalno-kemijskih svojstava odgovarajućeg elektrolitskog sustava. Daljnja istraživanja trebaju ići u smjeru optimizacije procesa $s$ ciljem dobivanja optimalne vrijednosti potrošnje ogrjevne pare. S obzirom na to da je koeficijent prolaza topline pretpostavljen, daljnja istraživanja mogu ići u smjeru određivanja koeficijenta prolaza topline na osnovu materijala od kojeg je izrađen izmjenjivač topline i na osnovu njegovih dimenzija. Kreirani procesni simulator za analizu i simulaciju dvostupnjevitog isparivačkog sustava i vakuumskog kristalizatora ne može se primjenjivati za jednostupnjeviti isparivački sustav i vakuumski kristalizator, kao ni na trokomponentni elektrolitski sustav, što predstavlja ograničenje.

\section{Zaključak}

$\mathrm{S}$ ciljem smanjenja potrošnje energije u dvostupnjevitom isparivačkom sustavu potrebno je iskoristiti generiranu sekundarnu paru prvog isparivačkog stupnja kao ogrjevni medij u drugom isparivačkom stupnju. Miješanje toka matične otopine s polaznim tokom prije ulaza u isparivački stupanj također smanjuje potrošnju energije s obzirom na to da se miješanjem povećava sadržaj soli. Rješavanje matematičkog modela kombinacije procesa isparavanja i kristalizacije u programu Microsoft Excel s VBA omogućava analizu i simulaciju navedenih procesa za bilo koje druge poznate varijable. Nedostatak kreiranog procesnog simulatora je u tome što se može primijeniti samo za dvostupnjevito isparavanje i nema mogućnost primjene za trokomponentni elektrolitski sustav

\section{Popis kratica i simbola}

\section{List of abbreviations and symbols}

A - parametar u Antoineovoj korelaciji, -

- parameter in Antoine's correlation, -

$A_{l} \quad-$ površina za prijenos topline prvog isparivačkog stupnja, $\mathrm{m}^{2}$

- heat transfer area of the first evaporator stage, $\mathrm{m}^{2}$

$A_{\text {II }} \quad$ - površina za prijenos topline drugog isparivačkog stupnja, $\mathrm{m}^{2}$

- heat transfer area of the second evaporator stage, $\mathrm{m}^{2}$
B

- parametar u Antoineovoj korelaciji, -

- parameter in Antoine's correlation, -

C - parametar u Antoineovoj korelaciji, -

- parameter in Antoine's correlation, -

$C_{1}{ }^{(1)} \quad-$ sadržaj soli u polaznom toku iskazan množinskim udjelom, 1

- salt content in the feed flow expressed in multiplier share, 1

$C_{1}{ }^{(3)}-$ sadržaj soli u koncentriranom toku prvog isparivačkog stupnja iskazan množinskim udjelom, 1

- salt content in the concentrated flow of the first evaporator stage expressed in multiplier share, 1

$C_{1}{ }^{(5)} \quad$ - sadržaj soli u koncentriranom toku drugog isparivačkog stupnja iskazan množinskim udjelom, 1

- salt content in the concentrated flow of the second evaporator stage expressed in multiplier share, 1

$C_{1}{ }^{(8)} \quad-$ sadržaj soli u toku matične otopine iskazan množinskim udjelom, 1

- salt content in the parent solution flow expressed in multiplier share, 1

$C_{1}{ }^{(7)} \quad$ - sadržaj soli u toku kristalnog produkta iskazan množinskim udjelom, 1

- salt content in the crystal product flow expressed in multiplier share, 1

$C_{1}{ }^{(\mathrm{kr})}-$ sadržaj soli u toku kristala iskazan množinskim udjelom, 1

- salt content in the crystal flow expressed in multiplier share, 1

$c_{p, 1} \quad-$ specifični toplinski kapacitet polaznog sistema, $\mathrm{kJ} \mathrm{kg}^{-1} \mathrm{~K}^{-1}$

- specific heat capacity of the feed system, $\mathrm{kJ} \mathrm{kg}^{-1} \mathrm{~K}^{-1}$

$c_{p, 3} \quad-$ specifični toplinski kapacitet koncentriranog toka prvog isparivačkog stupnja, $\mathrm{kJ} \mathrm{kg}^{-1} \mathrm{~K}^{-1}$

- specific heat capacity of the concentrated flow of first evaporator stage, $\mathrm{kJ} \mathrm{kg}^{-1} \mathrm{~K}^{-1}$

$C_{p, 5} \quad-$ specifični toplinski kapacitet koncentriranog toka drugog isparivačkog stupnja, $\mathrm{kJ} \mathrm{kg}^{-1} \mathrm{~K}^{-1}$

- specific heat capacity of the concentrated flow of second evaporator stage, $\mathrm{kJ} \mathrm{kg}^{-1} \mathrm{~K}^{-1}$

$c_{p, 7} \quad-$ specifični toplinski kapacitet kristalnog produkta, $\mathrm{kJ} \mathrm{kg}^{-1} \mathrm{~K}^{-1}$

- specific heat capacity of the crystal flow, $\mathrm{kJ} \mathrm{kg}^{-1} \mathrm{~K}^{-1}$

$\mathrm{d} t$

- povišenje temperature vrelišta u prvom isparivačkom stupnju, ${ }^{\circ} \mathrm{C}$

- boiling temperature rise in the first evaporator stage, ${ }^{\circ} \mathrm{C}$

$\hat{h}_{1} \quad$ - specifična entalpija polaznog toka, $\mathrm{kJ} \mathrm{kg}^{-1}$

- specific enthalpy of the feed flow, $\mathrm{kJ} \mathrm{kg}^{-1}$ 
$\hat{H}_{2} \quad$ - specifična entalpija generirane sekundarne pare prvog isparivačkog stupnja, $\mathrm{kJ} \mathrm{kg}^{-1}$

- specific enthalpy of the generated secondary vapour of the first evaporator stage, $\mathrm{kJ} \mathrm{kg}^{-1}$

$\hat{h}_{3} \quad$ - specifična entalpija koncentriranog toka prvog isparivačkog stupnja, $\mathrm{kJ} \mathrm{kg}^{-1}$

- specific enthalpy of the concentrated flow of the first evaporator stage, $\mathrm{kJ} \mathrm{kg}^{-1}$

$\hat{H}_{4} \quad$ - specifična entalpija generirane sekundarne pare drugog isparivačkog stupnja, $\mathrm{kJ} \mathrm{kg}^{-1}$

- specific enthalpy of the generated secondary vapour of the second evaporator stage, $\mathrm{kJ} \mathrm{kg}^{-1}$

$\hat{h}_{5} \quad$ - specifična entalpija koncentriranog toka drugog isparivačkog stupnja, $\mathrm{kJ} \mathrm{kg}^{-1}$

- specific enthalpy of the concentrated flow of the second evaporator stage, $\mathrm{kJ} \mathrm{kg}^{-1}$

$\hat{h}_{6} \quad-$ specifična entalpija toka suspenzije, $\mathrm{kJ} \mathrm{kg}^{-1}$

- specific enthalpy of the suspension flow, $\mathrm{kJ} \mathrm{kg}^{-1}$

$\hat{h}_{7} \quad-$ specifična entalpija kristalnog produkta, $\mathrm{kJ} \mathrm{kg}^{-1}$

- specific enthalpy of the crystal product flow, $\mathrm{kJ} \mathrm{kg}^{-1}$

$\hat{H}_{8} \quad$ - specifična entalpija generirane sekundarne pare vakuumskog kristalizatora, $\mathrm{kJ} \mathrm{kg}^{-1}$

- specific enthalpy of the generated secondary vapour of the vacuum crystallizer, $\mathrm{kJ} \mathrm{kg}^{-1}$

$\hat{h}_{9} \quad$ - specifična entalpija matične otopine, $\mathrm{kJ} \mathrm{kg}^{-1}$

- specific enthalpy of the parent solution flow, $\mathrm{kJ} \mathrm{kg}^{-1}$

$K_{1} \quad-$ koeficijent prolaza topline u prvom isparivačkom stupnju, $\mathrm{W} \mathrm{m}^{-2} \mathrm{~K}^{-1}$

- heat transfer coefficient in the first evaporator stage, $\mathrm{W} \mathrm{m}^{-2} \mathrm{~K}^{-1}$

$K_{\|} \quad-$ koeficijent prolaza topline $\mathrm{u}$ drugom isparivačkom stupnju, $\mathrm{W} \mathrm{m}^{-2} \mathrm{~K}^{-1}$

- heat transfer coefficient in the second evaporator stage, $\mathrm{W} \mathrm{m}^{-2} \mathrm{~K}^{-1}$

$\bar{m}_{1} \quad-$ protok polaznog toka, $\mathrm{kg} \mathrm{h}^{-1}$

- feed flow, $\mathrm{kg} \mathrm{h}^{-1}$

$\bar{m}_{2} \quad$ - protok generirane sekundarne pare prvog isparivačkog stupnja, $\mathrm{kg} \mathrm{h}^{-1}$

- flow of the generated secondary vapour of the first evaporator stage, $\mathrm{kg} \mathrm{h}^{-1}$

$\bar{m}_{3} \quad$ - protok koncentriranog toka prvog isparivačkog stupnja, $\mathrm{kg} \mathrm{h}^{-1}$

- flow of the concentrated flow of the first evaporator stage, $\mathrm{kg} \mathrm{h}^{-1}$

$\bar{m}_{4} \quad$ - protok generirane sekundarne pare drugog isparivačkog stupnja, $\mathrm{kg} \mathrm{h}^{-1}$

- flow of the generated secondary vapour of the second evaporator stage, $\mathrm{kg} \mathrm{h}^{-1}$

$\bar{m}_{5} \quad-$ protok koncentriranog toka drugog isparivačkog stupnja, $\mathrm{kg} \mathrm{h}^{-1}$

- flow of the concentrated flow of the second evaporator stage, $\mathrm{kg} \mathrm{h}^{-1}$

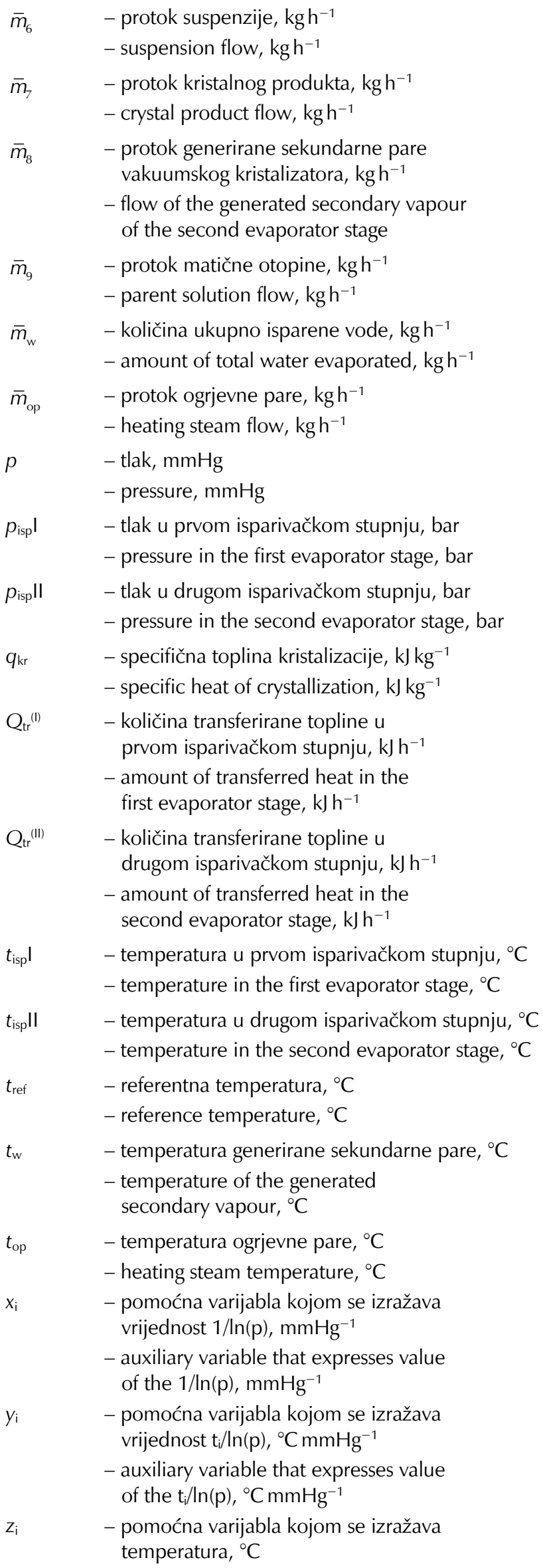




$$
\begin{aligned}
& \text { - auxiliary variable that expresses value } \\
& \text { of the temperature, }{ }^{\circ} \mathrm{C} \\
& \Delta \hat{H}_{\mathrm{v}}^{\left({ }^{(I)}\right.} \quad \text { - latentna toplina isparavanja ogrjevne } \\
& \text { pare, } \mathrm{kJ} \mathrm{kg}^{-1} \\
& \text { - latent heat of evaporation of the heating } \\
& \text { steam, } \mathrm{kJ} \mathrm{kg}^{-1} \\
& \Delta \hat{H}_{\mathrm{v}}{ }^{\text {(tispl) }} \text { - latentna toplina isparavanja generirane } \\
& \text { sekundarne pare prvog isparivačkog } \\
& \text { stupnja, } \mathrm{kJ} \mathrm{kg}^{-1} \\
& \text { - latent heat of evaporation of the generated } \\
& \text { secondary vapour of the first evaporator } \\
& \text { stage, } \mathrm{kJ} \mathrm{kg}^{-1} \\
& \Delta t_{\mathrm{sr}}^{\left({ }^{(1)}\right.} \quad-\text { srednja temperaturna razlika u } \\
& \text { prvom isparivačkom stupnju, }{ }^{\circ} \mathrm{C} \\
& \text { - medium temperature difference } \\
& \text { in the first evaporator stage, }{ }^{\circ} \mathrm{C} \\
& \Delta t_{\mathrm{sr}}{ }^{(\mathrm{II})} \quad \text { - srednja temperaturna razlika u } \\
& \text { drugom isparivačkom stupnju, }{ }^{\circ} \mathrm{C} \\
& \text { - medium temperature difference in the } \\
& \text { second evaporator stage, }{ }^{\circ} \mathrm{C}
\end{aligned}
$$

\section{Literatura \\ References}

1. J. D. Seader, E. J. Henley, S. K. Roper, Separation process principles, $2^{\text {nd }}$ Ed., John Wiley \& Sons, Inc., New York, 1998., str. 13.

2. M. Jotanović, M. Suljkanović, Analiza kristalizacije natrijum hlorida iz rastvora u vakuum kristalizeru sa recirkulacijom suspenzije, Hem. Ind. 63 (2009) 95-100, doi: https://doi.org/10.2298/HEMIND0902095J.

3. K. Thomsen, P. Rasmussen, R. Gani, Simulation and optimization of fractional crystallization processes, Chem. Eng. Sci. 53 (1998) 1551-1564, doi: https://doi.org/10.1016/S0009-2509(97)00447-8.

4. K. Thomsen, P. Rasmussen, R. Gani, Correlation and prediction of thermal properties and phase behaviour for a class of aqueous electrolyte systems, Chem. Eng. Sci. 51 (1996) 3675-3683, doi: https://doi.org/10.1016/00092509(95)00418-1.

5. B. Fitch, How to design fractional crystallization processes, Ind. Eng. Chem. 62 (1970) 6-33, doi: https://doi.org/10.1021/ie50732a004.

6. P. Sharan, S. Bandyopadhyay, Integration of thermo-vapor compressor with multiple-effect evaporator, App. Energy 184 (2016) 560-573,

doi: https://doi.org/10.1016/j.apenergy.2016.10.037.

7. M. Busch, W. E. Mickols, Reducing energy consumption in seawater desalination, Desalination 165 (2004) 299-312, doi: https://doi.org/10.1016/j.desal.2004.06.035.

8. M. Suljkanović, M. Jotanović, E. Ahmetović, N. Ibrić, Multivariant simulator for vacuum cooling processes of three component electrolyte systems, Hem. Ind. 64 (2010) 21-33, doi: https://doi.org/10.2298/HEMIND1001021S.

9. J. B. Hillenbrand, A. W. Westerberg, The synthesis of multipleeffect evaporator systems using minimum utility insights - I. A cascaded heat representation, Comput. Chem. Eng. 12 (1988) 611-624, doi: https://doi.org/10.1016/0098-1354(88)80003-6.

10. H. Nishitani, E. Kunugita, The optimal flow-pattern of multiple effect evaporator systems, Comput. Chem. Eng. 3 (1979) 261-268, doi: https://doi.org/10.1016/0098-1354(79)80044-7.

11. D. Kumar, V. Kumar, V. P. Singh, Modeling and dynamic simulation of mixed feed multi-effect evaporators in paper industry, Appl. Math. Model. 37 (2013) 384-397. doi: https://doi.org/10.1016/j.apm.2012.02.039.

12. Q. Ruan, H. Jiang, M. Nian, Z. Yan, Mathematical modeling and simulation of countercurrent multiple effect evaporation for fruit juice concentration, J. Food Eng. 146 (2015) 243251 , doi: https://doi.org/10.1016/j.jfoodeng.2014.09.015.

13. P. Dingemans, L. L. Dijkgraaf, The vapour pressure of saturated solutions of sodium nitrate in water, Recl. Trav. Chim. Pays-Bas 67 (1948) 231-234, doi: https://doi.org/10.1002/recl.19480670308. 


\title{
SUMMARY
}

\section{Analysis of Evaporation and Crystallization of Potassium Nitrate from Water Solution in Two-stage Evaporation System and Vacuum Crystallizer}

\author{
Ervin Karić* and Nesib Mustafić
}

Computational analysis of salt separation from two-component electrolytic system is presented. A case study of an electrolytic system $\mathrm{KNO}_{3}-\mathrm{H}_{2} \mathrm{O}$ was used to illustrate the analysis of evaporation and crystallization. The following processes are considered: two-stage evaporation system and vacuum crystallizer with adiabatic cooling. A mathematical model of the two-stage evaporation system and vacuum crystallizer was developed. The mathematical model is comprised of algebraic equations. The proposed model was developed in Microsoft Excel with VBA (Visual Basic for Applications). The developed model enables analysis of existing or design of new evaporation and crystallization processes. The developed model can be applied for any two-component electrolyte system, but requires the input of physicochemical properties related to corresponding electrolyte system.

\section{Keywords}

Electrolytic system, evaporation system, vacuum crystallization, mathematical model 